\title{
Microwave Surface Reflection Method for Soil Moisture Determination Using frequency of $1.7-2.6 \mathrm{GHz}$
}

\author{
Yap, C. W. ${ }^{1,2}$, Mardeni R. ${ }^{1} \&$ Ahmad, N. N. ${ }^{1}$ \\ ${ }^{1}$ Faculty of Engineering, Multimedia University, Cyberjaya, Selangor, Malaysia \\ ${ }^{2}$ Asia Pacific University of Technology and Innovation, Faculty of Computing, Engineering and Technology, \\ TPM, Bukit Jalil, Kuala Lumpur, Malaysia \\ Correspondence: Mardeni R., Faculty of Engineering, Multimedia University, Cyberjaya, Selangor, Malaysia. \\ Tel: 603-8312-5481. E-mail: mardeni.roslee@mmu.edu.my
}

Received: June 2, 2015

Accepted: September 15, 2015

Online Published: November 30, 2015

doi:10.5539/mas.v9n13p71

URL: http://dx.doi.org/10.5539/mas.v9n13p71

\begin{abstract}
Soil moisture is one of the critical components to be investigated in civil, geological and agricultural works. This is because the parameter can affect the physical and electromagnetic characteristics of soil, such as density and permittivity and this can further restricts soil application. Unfortunately, finding a suitable non-destructive model for accurate soil moisture determination is challenging. In this article, the concept and development of soil moisture determination via ground penetrating radar (GPR) principle and surface reflection method is explained. The system is designed to be used with standard horn antenna with a frequency of 1.7-2.6 GHz along with vector network analyzer (VNA). The proposed system can measure soil moisture of three types of soil samples such as sand, loamy, and clay with high degree of accuracy. In this research, microwave surface reflection method is applied to analyze the effect of soil moisture with its electrical properties using our novel GPR principle. The result of the research is promising with high percentage of agreement with Topp theoretical value. The values are $31 \%$ to $61 \%$ for sand, $5 \%$ to $42 \%$ for clay, and $44 \%$ to $54 \%$ for loamy. For validation on the system, a new type of soil is used for measurement, and the result has an accuracy of $93 \%$. By using the proposed developed models, soil moisture estimation can be easily determined with minimal data input through a novelty GPR surface reflection method.
\end{abstract}

Keywords: GPR, soil moisture, surface reflection, microwave, radio wave

\section{Introduction}

Immense growth in radar technologies has increased its role in a variety of fields, and ground penetrating radar (GPR) is seen to gain tractions for increasing applications. Ground penetrating radar (GPR) principle has been widely employed in non-destructive tests (NDT) for a variety of fields (Daniels, 2008). The relationships of soil physical and electrical characteristics are often discussed by some researchers and these properties contributed in many aspects of structure estimation (Daniels, 1988). However, results often associated with drawbacks. Other researchers proposed a study of GPR measurement that relates density and attenuation of road pavement slabs, a frequency range of 1.7-2.6 GHz. The experiment was constructed using a signal generator, spectrum analyzer, directional coupler with adapter and a horn antenna (Peters, 1984). But the drawback of the study was that soil moisture cannot be measured.

Jusoh studied the moisture content in mortar at near relaxation frequency, and developed an equation from the study (2011), and parameter water content and attenuation with mortar is correlated. But, the drawback of the research is that it is simple and soil characterization overlooked and not considered a variable in equation (Jusoh, 2011). At another study, permittivity of a material is measured using a network analyzer connected to a GPR antenna and a resonator, but the drawback is that they are not able to characterize the sample permittivity (Abdullah, 2009). Another current commonly used method of soil moisture measurement is coring, which involved physical removal of soil from the ground (Daniels, 2008; Peters, 1984). After removing the soil from the ground, the soil is brought to the lab for moisture measurement. Unfortunately, coring is time-consuming and destructive to the eco-system.

The study presented here is to investigate a better alternative to measure soil moisture via radio wave reflection 
method. In this article, we proposed a soil moisture model which gives a faster moisture estimation that can benefit agricultural surveyors performing routine soil moisture test. We are expecting to enable in-situ soil moisture measurement without damaging the soil eco-system.

\section{Electromagnetic Property of Soil}

Electromagnetic property of soil is another critical area to be assessed. Each soil type possesses unique characteristics such as permittivity, permeability and conductivity (Tarantino, 2009). These characteristics are widely research as they influence moisture measurement. As with standard research methods, this study limits to permittivity determination. The notion of the work is that theoretical value of soil moisture is developed as a benchmark for the measurement result performed in the lab. This can be completed via comparing the result with nominal range of permittivity and development of electromagnetic method for radar.

\subsection{Nominal Range of Return Loss}

The nominal range for different soil of sand, loamy, and clay soil are shown in Table 1 (Turk, 2011). Referring to Table 1, loamy soil and clayey soil has the closest relative dielectric constant or permittivity, which is in between $3-30$. The relative dielectric constant of sandy soil is on the upper range which is in between $10-30$. These permittivity data with corresponding return loss are used as a benchmark for the study.

Table 1. Typical soil characteristics of various soil samples shown with relative dielectric constant and return loss

\begin{tabular}{lll}
\hline Soil Sample & Relative Dielectric Constant & Loss at $1 \mathrm{GHz}(\mathrm{dB} / \mathrm{m})$ \\
\hline Sandy soil (wet) & $10-30$ & $10-50$ \\
Clayey soil & $4-30$ & $10-2000$ \\
Loamy soil & $3-30$ & $1-500$ \\
\hline
\end{tabular}

\subsection{Theoretical Estimation}

As with standard research method, theoretical basis is established for benchmarking. However, this is a challenging task as few researches are conducted to determine soil moisture with GPR. Hence the theoretical method of soil moisture is derived from Time Domain Reflectometry (TDR) method. In 1980, prominent researcher Topp and his team conducted a study via electromagnetic method and developed a formula to correlate soil water content with permittivity. The experiments were completed in laboratory where samples were positioned in a coaxial transmission line and the complex dielectric permittivities were measured from dry soil up to saturated condition. Empirical model of soil moisture content in terms of dielectric permittivity was introduced and expressed as (1) and (2) (Topp, 1980).

$$
\begin{aligned}
v=-5.3 \times & 10^{-2}+2.92 \times 10^{-2}-5.5 \times 10^{-4}+4.3 \times 10^{-6} \\
& =3.03+9.3{ }_{v}+146.0{ }_{v}{ }^{2}+76.7{ }_{v}{ }^{3}
\end{aligned}
$$

where $\varepsilon$ represents real part of complex relative permittivity and $\theta_{v}$ represents volumetric water content. Rearranging (1) for permittivity provides us with (2), which is known as the standard Topp equation (Topp, 1980).

Researcher Hallikainen had further the research and proposed a polynomial equation that correlates water content and permittivity, with the addition of a new variable - soil type (1985).

$$
=\left(a_{0}+a_{1} S+a_{2} C\right)+\left(b_{0}+b_{1} S+b_{2} C\right) \quad{ }_{v}+\left(c_{0}+c_{1} S+c_{2} C\right) \quad v^{2}
$$

where $a, b$, and $c$ are polynomial coefficients, $S$ is sandy ratio and $C$ is clay ratio. In the study, soil types have shown that dielectric permittivity changes significantly in the lower frequency range, particularly between $1.4 \mathrm{GHz}$ to $5 \mathrm{GHz}$. According to the study, the permittivity at $1.4 \mathrm{GHz}$ is represented with polynomial coefficients as (4) and (5).

$$
\begin{aligned}
& '=(2.862-0.012 S+0.001 C)+(3.803+0.462 S-0.341) \quad{ }_{v}+(119.006+0.5 S+0.633 C) \quad v^{2} \\
& "=(0.356-0.003 S-0.008 C)+(5.507+0.044 S-0.002) \quad v+(17.753-0.313 S+0.206) \quad v^{2}
\end{aligned}
$$

where $\varepsilon$ ' and $\varepsilon$ " are respectively the real part and imaginary part of complex dielectric permittivity. In this work, Topp and Hallikainen equations are used as a benchmark for the result. In our work, the idea was these equations will be correlated with the return loss, and integrated with the measurement using GPR principle.

Permittivity obtained from Topp (2) and Hallikainen (3) are derived further with GPR method. In the 
investigation of thin layers in concrete using reflection of GPR signals and pulse lengths, the permittivity of a material, $\varepsilon$ can be calculated in the expression of reflection coefficient, $\Gamma$ by using (6) (Daniels, 2008).

$$
\varepsilon=\left(\frac{1+\Gamma}{1-\Gamma}\right)^{2}
$$

In our work, the equipment setup is conducted in the frequency of $1.7 \mathrm{GHz}$ to $2.6 \mathrm{GHz}$. This range is within the microwave frequency range of $300 \mathrm{MHz}$ to $300 \mathrm{GHz}$, where return loss can be correlated to reflection coefficient by (7).

$$
R L=-20 \log \mid \Pi
$$

Following these equations, permittivity of a material can be converted to return loss. Through the derivation, permittivity from Topp (2) and Hallikainen (3) can be expressed in terms of return loss. The theoretical determinations are then compared with the measurements from this work.

\section{Methodology}

This proposed study was implemented by investigating the properties of soil samples, collecting data from laboratory experiments, performed analysis and integrated the result with existing research. Flowchart of the study in this project is shown in Figure 1. Flowchart of the study shows that soil samples are prepared through processing, equipment is setup and measurement conducted, data is analyzed, and soil moisture model is verified and developed.

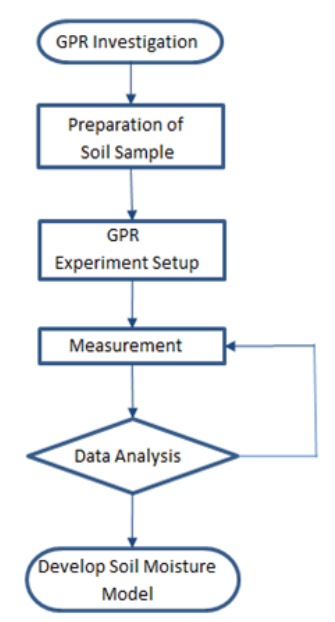

Figure 1. Flowchart of the study

\subsection{Properties of Soil Sample}

In this study, three types of soil were determined as samples in the lab experiment. The typical moisture content for three types of soil are also shown in Table 2, where moisture content, $w$, is the ratio of weight of solids (g) to weight of water (g) in percentage (Turk, 2011).

Table 2. Soil texture classification of soil samples with equivalent diameter size and typical moisture content.

\begin{tabular}{ccc}
\hline $\begin{array}{c}\text { Soil } \\
\text { Type }\end{array}$ & Equivalent Diameter Size $(\mathrm{mm})$ & Typical Moisture Content, $w(\%)$ \\
\hline Sand & $0.05-2.00$ & $5-15$ \\
Silt & $0.02-0.05$ & $5-40$ \\
Clay & $<0.02$ & $10-50$ (or more) \\
\hline
\end{tabular}

\subsection{Soil Characterization}

In this study, soil samples are selected and prepared through characterization process. Soil samples determined are clay, sand, and loamy, as these three types of soil are the standard for various different soil compositions. 
Soil samples are collected and prepared as laboratory tests objects. The samples are weighed before drying, as the drying process takes 24 hours in the oven at $110^{\circ} \mathrm{C}$ per British Standards (British Standard Institution, 1990). After drying, the soil is weighed and the moisture content are calculated with an equation in the simplest form:

$$
\theta_{v}=\frac{V_{\text {water }}}{V_{\text {total }}}
$$

where $\quad v$ is volumetric soil moisture, $V_{\text {water }}$ is the water content, $V_{\text {total }}$ is the total volume content including soil volume, water volume and air volume. This equation can be further developed into the following form (Argonne National Laboratory, 2014).

$$
\theta_{v}=\frac{W_{\text {moist }}-W_{d r y}}{V_{\text {total }} \rho_{\text {water }}}
$$

where $W_{\text {moist }}$ is the weight of wet soil, $W_{d r y}$ is the weight of dry soil, $V_{\text {total }}$ is the total volume, $\rho_{\text {water }}$ is the density of water.

After the drying process, soil samples prepared is in the stage of soil characterization. In electromagnetic approach, soil dielectric models are used to relate physical characteristics of soil with its electrical properties. In this study, the soil physical parameters are to be determined before experiment is conducted. Physical parameters of soil types are determined using sieve test analysis method, as approved by (British Standard Institution, 1990).

The sieving process uses different screen size of sieve containers as shown in Figure 2. In this process, samples are placed in the top of the stacked sieve containers. The sieve containers are arranged as the containers with the largest screen size stays at the top and the finest screen size stays at the bottom. The stacked containers are placed in the sieve shaker for 10 minutes as in Figure 3. During the sieving process, the coarse particles stay at the top and progressively to the finest particles at the bottom. The particles collected at each stage are weighed and the percentage of clay and sand is determined.

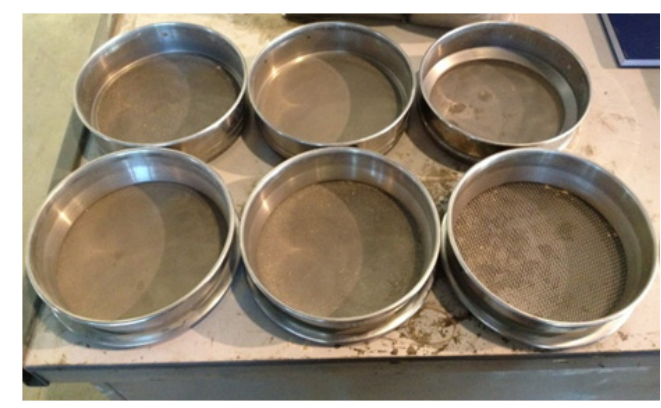

Figure 2. Sieve containers

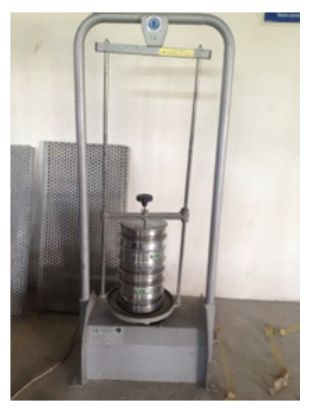

Figure 3. Sieve machine

Result of the sieving analysis is collected and analysed. Based on the classification of soil types in Table 2, soil components are catergorized and shown in Table 3.

Table 3. Result of soil sample characterization shown with various soil samples in different soil components.

\begin{tabular}{lllll}
\hline No & Soil Sample & Clay (\%) & Sand (\%) & Silt (\%) \\
\hline 1 & Sand & 0.02 & 0.96 & 0.02 \\
2 & Clay & 0.5 & 0.37 & 0.13 \\
3 & Loamy & 0.08 & 0.84 & 0.08 \\
\hline
\end{tabular}

Referring to Table 3, sand sample contains $96 \%$ of sand per classification and this is regarded as pure sand. Clay sample contains $37 \%$ of sand and $5 \%$ of clay. Loamy soil contains $84 \%$ of sand and $8 \%$ of clay. This shows a diverse sample of soil components within the soil samples.

\section{Measurement Setup}

In this work, the experiment is summarized in a block diagram as in Figure 4. Referring to Figure 5, the length, 
width and thickness of the glass container are $0.4 \mathrm{~m}, 0.6 \mathrm{~m}$ and $0.8 \mathrm{~m}$, respectively. Also, $h$ is the soil thickness and $d=0.3 \mathrm{~m}$ is the distance from antenna to the soil surface. The antenna height and sample surface area are calibrated and optimization is performed in order to comply with GPR setup requirement.

\subsection{Experiment Setup}

The proposed experiment equipment setup is prepared with Vector Network Analyzer (VNA), standard horn antenna, and soil samples. The block diagram of the setup is shown in Figure 4. Referring to the block diagram, electromagnetic waves are directed to the soil via transmitter in standard horn antenna. Waves are reflected to the receiver of the antenna, and results is collected and displayed on the VNA.

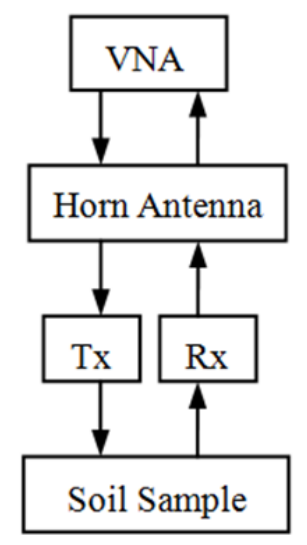

Figure 4. Block diagram of the study

\subsection{Equipment Setup}

The objective of the experiment is to obtain the soil return loss in $\mathrm{dB}$ for each step of soil moisture. The data measured is used to propose a new soil moisture model. The setup and experiment procedure are followed.

The experiment is to be conducted in a laboratory with horn antenna, vector network analyzer (VNA), N-type cable, glass container, soil samples and metal sheet. VNA used is manufactured by Agilent Technologies, model E5062A. The VNA operates in the range of $300 \mathrm{kHz}-3 \mathrm{GHz}$, and support the horn antenna operates in the range of $1.7 \mathrm{GHz}$ to $2.6 \mathrm{GHz}$. The equipment setup is shown in Figure 5, the setup is arranged with distance determined and components placed according to the GPR principle.

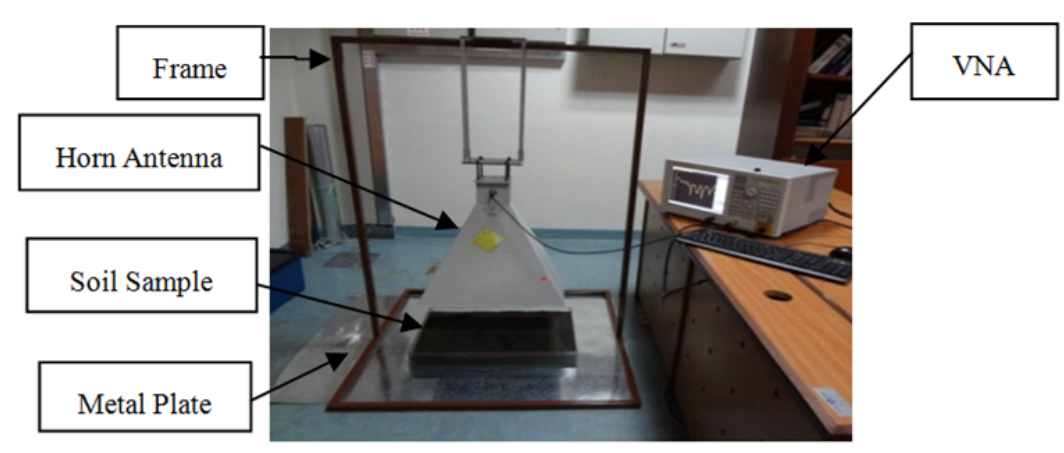

Figure 5. Lab measurement setup with standard horn antenna, antenna frame, soil samples, metal plate and VNA

The soil sample is to be formed into a rectangular shape test bed, placed in a glass container. The distance between horn antenna and the test bed is assessed with GPR technique. GPR operates in the near-field region and the distance $d$ fulfills the requirement. In the near-field region, distance $d$ is determined in between $d_{1}$ and $d_{2}$ (Amineh, 2011).

$$
d_{1}=
$$




$$
d_{2}=\frac{2 D^{2}}{\lambda}
$$

where $\lambda$ is wavelength and $D$ is the largest dimension of the antenna in meters (Daniels, 2008). Since the antenna is operating from $1.7 \mathrm{GHz}$ to $2.6 \mathrm{GHz}$, the wavelength ranges from $0.111 \mathrm{~m}$ to $0.177 \mathrm{~m}$. Near-field radiating region $d$, for the antenna is between $0.177 \mathrm{~m}$ to $3.064 \mathrm{~m}$. For this study, the proposed distance from antenna to soil surface $d$ is $0.30 \mathrm{~m}$ since it is in the near-field radiating region and conveniently accessible for measurement.

Further, sample size determination requires the determination of effective aperture of the antenna, $A_{e}$. The effective aperture is determined by (12).

$$
A_{e}=\frac{\lambda^{2}}{4 \pi} G
$$

where $\lambda$ is wavelength and $G$ is antenna gain. As provided by the manufacturer, antenna gain is $15 \mathrm{~dB}$. For the frequency of $1.7 \mathrm{GHz}$ to $2.6 \mathrm{GHz}$, effective aperture of the antenna $A_{e}$, is determined to be from $304.465 \mathrm{~cm}^{2}$ to $779.430 \mathrm{~cm}^{2}$. Sample size container is built slightly larger than the calculated physical aperture to minimize impractical data during measurement. Hence, radiated energy from the antenna is able to be transmitted to the whole soil surface area so that the maximum energy from the soil could be reflected and captured by the antenna.

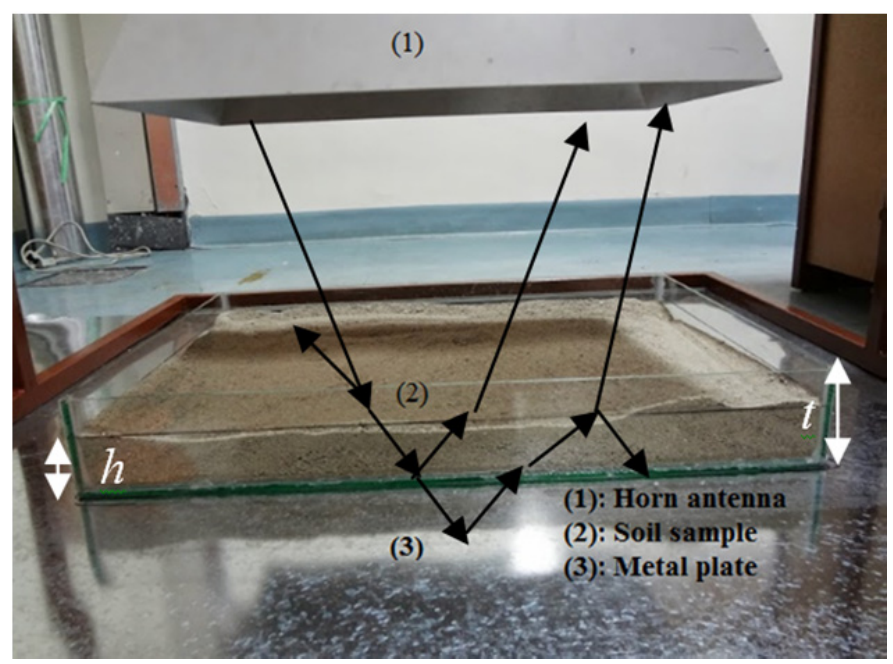

Figure 6. Base of the soil sample with antenna, soil sample and metal plate

The sample dimension is proposed with its height $h$, width $w$, and length $l$, as $5 \mathrm{~cm}, 60 \mathrm{~cm}$ and $40 \mathrm{~cm}$, respectively. The volume of soil, $V_{b}=h \times w \times l$ is calculated as $12,000 \mathrm{~cm}^{3}$. A metal sheet is placed at the bottom of the glass container as a perfect reflector for maximum reflection during measurement, and it minimizes noise and reflected signal from the floor and the surrounding. The setup which include all component as shown in Figure 6.

In free space measurement as in this study, multiple reflections are considered to be one of the main error sources. This is clearly shown in the study of attenuation and phase shift measurements. Multiple reflections occur within sample, and between antenna and sample (Geuzaine, 2005).

Several methods are applied to reduce the influence of multiple reflections. For multiple reflections within the sample, it can be minimized by increasing the sample thickness so that the attenuation of material sample is larger than 10 decibels (dB) (Kaatze, 2007). For multiples reflections between antenna and sample, several methods were proposed. The first method involves increasing the separation of the antennas (De Kool, 2006), but this will cause diffraction at the edge of the sample. For the second method, antenna or sample is moved along the normal axis of the two antennas and the measured results are averaged (Hasar, 2009), but it involves mounting equipment, complicated measurement methods and time consuming. The third method applies averaging the attenuation over a frequency band, which is applied in this study.

\section{Wave Modeling}

It is essential to model wavel travel in the equipment setup, as wave propagation is an important characteristic to be investigated as GPR travels in waveform. Wave travel affects interaction with materials and measurement, especially in the field of GPR. In this study, the scenario of wave transmission and reflection is shown in Figure 
7. The incident wave radiates from the antenna propagates through several medium and reflects back. The figure illustrates the phenomena of wave propagation in a multi-layer structure. The propagating wave is partially reflected and transmitted at each interface between air-soil, soil-glass, glass-metal due to the different impedance of the two medium.

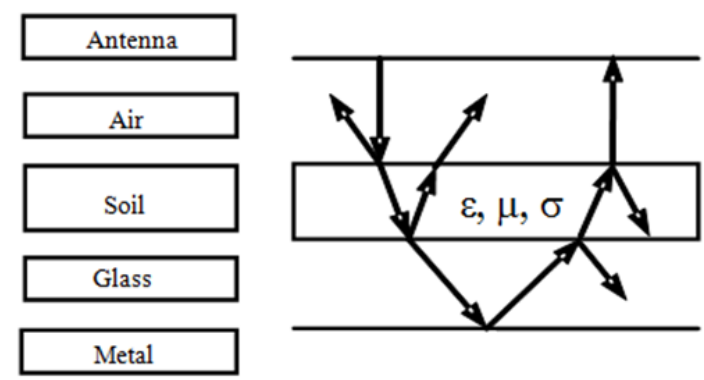

Figure 7. Wave propagation model shows that the waves from the antenna propagates through air, soil, glass, and metal

As wave travels through, part of the energy is reflected at the surface, transmitted and attenuated through the sample. Assuming that there is no dispersion, power can be measured on both sides of the sample and attenuation through the sample can be determined. This measurement is accurate if the reflections at the surface are small or can be neglected.

Generally there are four methods of GPR measurements, including reflected wave velocity, ground wave velocity, transmitted wave velocity between boreholes, surface reflection coefficient (Huisman, 2003). The first three methods use travel time as a base for permittivity and soil moisture measurement. The difference of wave travel time between dry soil and wet soil can determine the soil moisture content.

The last method of surface reflection coefficient or attenuation measurement is the most common method used in wave propagation. In this method, possible sources of error are the reflections between the sample and the surrounding medium. The magnitude of these errors can be reduced by standard calibration procedures. In this study, attenuation method is selected to be the method for determining soil moisture for various soil samples. The result obtained is accurate with minor errors across all soil samples.

\section{Experimental Results}

The data were collected from measurement using VNA with a sweep frequency of $1.7 \mathrm{GHz}$ to $2.6 \mathrm{GHz}$. In the experiment, the relationship between measured soil moisture and reflection coefficient was investigated. For each soil sample, the soil moisture was increased while the soil volume of $12,000 \mathrm{~cm}^{3} \mathrm{kept}$ constant throughout the study. The mass of sandy, clay and loamy soil were $15.6 \mathrm{~kg}, 14.4 \mathrm{~kg}$, and $9.6 \mathrm{~kg}$, respectively. Generally, compact soil restricts root growth and this depends on the type of soil. The effect of compact soil is far reaching that it restricts tree height (Zhao, 20100). As a guide, the bulk density for plant optimum growth is less than $1.6 \mathrm{~g} / \mathrm{cm}^{3}$ (USDA, 2008). Bulk density is calculated based on the mass measured and displayed in Table 4.

Table 4. Bulk density of three soil samples with various bulk density.

\begin{tabular}{ccccll}
\hline No & $\begin{array}{c}\text { Soil } \\
\text { Sample }\end{array}$ & $\begin{array}{c}\text { Mass } \\
(\mathrm{kg})\end{array}$ & $\begin{array}{c}\text { Bulk Density } \\
\left(\mathrm{kg} / \mathrm{m}^{3}\right)\end{array}$ & $\begin{array}{l}\text { Ideal Bulk Density for Plant } \\
\text { Growth }\left(\mathrm{g} / \mathrm{cm}^{3}\right)\end{array}$ & $\begin{array}{l}\text { Bulk Density that Restricts Root } \\
\text { Growth }\left(\mathrm{g} / \mathrm{cm}^{3}\right)\end{array}$ \\
\hline 1 & Sand & 15.6 & 1.3 & $<1.60$ & $>1.80$ \\
2 & Clay & 14.4 & 1.2 & $<1.10$ & $>1.47$ \\
3 & Loamy & 9.6 & 0.8 & $<1.40$ & $>1.65$ \\
\hline
\end{tabular}

Referring to Table 4, plant grows well in all soil types with bulk density of less than $1.6 \mathrm{~g} / \mathrm{cm}^{3}$. However, root growth is restriced when bulk density is beyond $1.8 \mathrm{~g} / \mathrm{cm}^{3}, 1.47 \mathrm{~g} / \mathrm{cm}^{3}$, and $1.65 \mathrm{~g} / \mathrm{cm}^{3}$ in sand, clay and loamy respectively.

As the soil sample is prepared, the experiment is performed in steps. For every step, $250 \mathrm{~cm}^{3}$ of water is added to the soil sample and water volume percentage is calculated. Return loss is measured from the VNA and normalized return loss is determined. Result is displayed in Table 5. 
Table 5. Measured return loss and normalized return loss with reference to step 0 .

\begin{tabular}{llllllllll}
\hline No & $\begin{array}{l}\text { Water } \\
\text { Volume } \\
\left(\mathrm{cm}^{3}\right)\end{array}$ & $\begin{array}{l}\text { Total } \\
\text { Volume } \\
\left(\mathrm{cm}^{3}\right)\end{array}$ & $\begin{array}{l}\text { Volumetric } \\
\text { Moisture }(\%)\end{array}$ & $\begin{array}{l}\text { Return Loss, } \\
(\mathrm{dB})\end{array}$ & & Direct & \multicolumn{2}{l}{$\begin{array}{l}\text { Return Loss, Normalized } \\
(\mathrm{dB})\end{array}$} \\
\cline { 5 - 9 } & 0 & 0 & 0 & Sand & Clay & Loamy & Sand & Clay & Loamy \\
\hline 0 & 0 & 12250 & 0.02 & 7.88 & 7.86 & 7.84 & N/A & N/A & N/A \\
1 & 250 & 12500 & 0.04 & 11.85 & 14.52 & 13.97 & 3.97 & 6.64 & 6.09 \\
2 & 500 & 12750 & 0.06 & 12.25 & 14.81 & 12.64 & 4.37 & 6.93 & 4.76 \\
3 & 750 & 13000 & 0.08 & 11.57 & 13.96 & 12.28 & 3.69 & 6.08 & 4.39 \\
4 & 1000 & 13250 & 0.09 & 11.76 & 12.99 & 11.92 & 3.88 & 5.11 & 4.04 \\
5 & 1250 & 13500 & 0.11 & 12.39 & 12.76 & 11.77 & 4.51 & 4.88 & 3.89 \\
6 & 1500 & 13750 & 0.13 & 12.38 & 13.20 & 11.61 & 4.50 & 5.31 & 3.73 \\
7 & 1750 & 14000 & 0.14 & 12.12 & 13.67 & 11.50 & 4.24 & 5.79 & 3.61 \\
8 & 2000 & 0.16 & 12.29 & 13.76 & 11.36 & 4.41 & 5.88 & 3.48 \\
9 & 2250 & 14250 & 12.35 & 13.74 & 11.08 & 4.47 & 5.86 & 3.20 \\
10 & 2500 & 14500 & 0.17 & 12.13 & 13.64 & 10.91 & 4.25 & 5.75 & 3.03 \\
11 & 2750 & 14750 & 0.19 & 11.76 & 13.15 & 10.82 & 3.87 & 5.27 & 2.94 \\
12 & 3000 & 15000 & 0.20 & 11.54 & 12.73 & 10.73 & 3.66 & 4.85 & 2.84 \\
13 & 3250 & 15250 & 0.21 & 11.33 & 12.44 & 10.72 & 3.45 & 4.56 & 2.84 \\
14 & 3500 & 15500 & 0.23 & 10.79 & 12.35 & 10.59 & 2.90 & 4.47 & 2.71 \\
15 & 3750 & 15750 & 0.24 & 10.14 & 12.40 & 10.42 & 2.25 & 4.52 & 2.53 \\
16 & 4000 & 16000 & 0.25 & 9.65 & 12.53 & 10.39 & 1.76 & 4.65 & 2.50 \\
\hline
\end{tabular}

The result of the dry soil sample is shown at first data, which is No. 0 of Table 5 , and this result is the reference for all other normalized results. For step No. $1,250 \mathrm{~cm}^{3}$ of water were added to the soil sample and the return loss is measured from VNA. The result of No 1 is deducted from No 0 and this is the normalized result. Normalized result only accounts for the changes in soil moisture with all other variables such as air to sample distance, cable and antenna impedance being constant.

\section{Results Analysis}

In the analysis, Topp and Hallikainen equations are used and compared with the results by using the previous approaches which is the soil moisture estimation path. The volume of water is used as an input to the equations to calculate soil permittivity. Equation (3) is used to determine reflection coefficient, and the coefficient is used to determine return loss. The theoretical values obtained are shown in Table 6.

Table 6. Normalized return loss in comparison with theoretical value of Topp and Hallikainen.

\begin{tabular}{|c|c|c|c|c|c|c|c|c|c|c|}
\hline \multirow[t]{3}{*}{ No } & \multirow{3}{*}{$\begin{array}{l}\text { Water Volume } \\
\left(\mathrm{cm}^{3}\right)\end{array}$} & \multirow{3}{*}{$\begin{array}{l}\text { Volumetric } \\
\text { Moisture } \\
(\%)\end{array}$} & \multicolumn{4}{|c|}{ Permittivity $\left(\varepsilon^{\prime}\right)$} & \multicolumn{4}{|c|}{ Return Loss, Calculated (dB) } \\
\hline & & & \multirow{2}{*}{ Topp } & \multicolumn{3}{|c|}{ Hallikainen } & \multirow{2}{*}{ Topp } & \multicolumn{3}{|c|}{ Hallikainen } \\
\hline & & & & Sand & Clay & Loamy & & Sand & Clay & Loamy \\
\hline 1 & 250 & 0.02 & 3.28 & 2.99 & 2.99 & 2.99 & 10.80 & 11.47 & 11.48 & 11.47 \\
\hline 2 & 500 & 0.04 & 3.63 & 3.21 & 3.20 & 3.21 & 10.13 & 10.95 & 10.97 & 10.95 \\
\hline 3 & 750 & 0.06 & 4.07 & 3.51 & 3.49 & 3.51 & 9.45 & 10.34 & 10.37 & 10.35 \\
\hline 4 & 1000 & 0.08 & 4.57 & 3.88 & 3.86 & 3.87 & 8.81 & 9.72 & 9.76 & 9.73 \\
\hline 5 & 1250 & 0.09 & 5.14 & 4.31 & 4.28 & 4.30 & 8.22 & 9.13 & 9.16 & 9.14 \\
\hline 6 & 1500 & 0.11 & 5.76 & 4.79 & 4.75 & 4.78 & 7.71 & 8.58 & 8.61 & 8.58 \\
\hline 7 & 1750 & 0.13 & 6.42 & 5.31 & 5.27 & 5.30 & 7.25 & 8.07 & 8.11 & 8.08 \\
\hline 8 & 2000 & 0.14 & 7.11 & 5.88 & 5.83 & 5.87 & 6.85 & 7.62 & 7.65 & 7.63 \\
\hline 9 & 2250 & 0.16 & 7.84 & 6.48 & 6.43 & 6.47 & 6.49 & 7.21 & 7.24 & 7.22 \\
\hline 10 & 2500 & 0.17 & 8.58 & 7.11 & 7.06 & 7.10 & 6.18 & 6.85 & 6.88 & 6.86 \\
\hline 11 & 2750 & 0.19 & 9.34 & 7.76 & 7.71 & 7.75 & 5.90 & 6.53 & 6.55 & 6.53 \\
\hline 12 & 3000 & 0.20 & 10.12 & 8.44 & 8.38 & 8.43 & 5.65 & 6.23 & 6.26 & 6.24 \\
\hline 13 & 3250 & 0.21 & 10.90 & 9.14 & 9.08 & 9.13 & 5.43 & 5.97 & 5.99 & 5.97 \\
\hline 14 & 3500 & 0.23 & 11.69 & 9.85 & 9.79 & 9.84 & 5.23 & 5.73 & 5.75 & 5.74 \\
\hline 15 & 3750 & 0.24 & 12.49 & 10.58 & 10.52 & 10.57 & 5.05 & 5.52 & 5.54 & 5.52 \\
\hline 16 & 4000 & 0.25 & 13.28 & 11.32 & 11.26 & 11.31 & 4.89 & 5.32 & 5.34 & 5.33 \\
\hline
\end{tabular}


The measured return loss was plotted with the corresponding theoretical value from Topp and Hallikainen value, as shown in Figure 8. Prefix $M$ in the legend reprersents measured data.

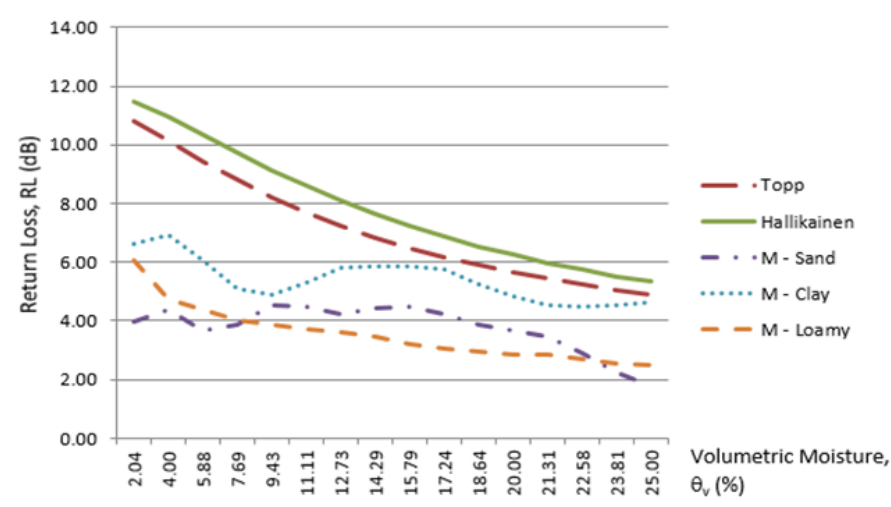

Figure 8. Plot of graph for normalized return loss in comparison with Topp and Hallikainen theoretical values.

From Figure 8, it is shows that return loss decreases as water content increases. Topp and Hallikainen equations generally agree with each other within a range of $10 \%$. The measurement of the soil, in particular loamy soil follows the curve but at a lower return loss. This is due to the different composition of soil that was used. The measurements of the three types of soil are shown in the polynomial equations (13) - (15). In these equations, return loss is expressed in terms of volumetric moisture. For example, in (13), return loss of sand, $R L_{\text {sand }}$ is expressed in terms of volumetric moisture, $\quad{ }_{v}$. This notation is followed by the subsequent equations.

$$
\begin{gathered}
R L_{\text {sand }}=-819.6 v_{v}^{3}+216.3 v^{2}-129.5 v+4.224 \\
R L_{\text {clay }}=-821 v^{3}+339.5 v^{2}-47.59 v+7.702 \\
R L_{\text {loamy }}=-530.1 v^{3}+270.2 v_{v}^{2}-51.88 v+6.759
\end{gathered}
$$

In order to observe the agreement between theoretical and measurement, the errors against theoretical value of Topp and Hallikainen are calculated using (16). Error percentage is summarized in Table 7.

$$
\text { Error }(\%)=\underline{\text { Measured }- \text { Actual }} \times 100
$$

Actual

Table 7. Error percentage of Topp and Hallikainen theoretical values with measured data

\begin{tabular}{lllllll}
\hline \multirow{2}{*}{ Volumetric Moisture (\%) } & \multicolumn{3}{l}{ Error with Topp (\%) } & \multicolumn{3}{c}{ Error with Hallikainen (\%) } \\
\cline { 2 - 7 } & Sand & Clay & Loamy & Sand & Clay & Loamy \\
\hline 2.04 & 63.21 & 38.53 & 43.62 & 65.39 & 42.16 & 46.95 \\
4.00 & 56.90 & 31.59 & 52.98 & 60.15 & 36.76 & 56.54 \\
5.88 & 60.95 & 35.68 & 53.51 & 64.37 & 41.31 & 57.59 \\
7.69 & 55.97 & 42.01 & 54.10 & 60.18 & 47.56 & 58.49 \\
9.43 & 45.14 & 40.71 & 52.72 & 50.65 & 46.66 & 57.47 \\
11.11 & 41.62 & 31.05 & 51.60 & 47.63 & 38.14 & 56.58 \\
12.73 & 41.50 & 20.19 & 50.14 & 47.56 & 28.45 & 55.31 \\
14.29 & 35.63 & 14.17 & 49.20 & 42.26 & 23.01 & 54.43 \\
15.79 & 31.21 & 9.73 & 50.71 & 38.20 & 18.91 & 55.72 \\
17.24 & 31.24 & 6.89 & 50.94 & 38.09 & 16.16 & 55.83 \\
18.64 & 34.35 & 10.75 & 50.24 & 40.73 & 19.43 & 55.08 \\
20.00 & 35.34 & 14.20 & 49.72 & 41.45 & 22.30 & 54.47 \\
21.31 & 36.55 & 16.10 & 47.70 & 42.36 & 23.78 & 52.49 \\
22.58 & 44.53 & 14.63 & 48.19 & 49.44 & 22.19 & 52.78 \\
23.81 & 55.39 & 10.66 & 49.88 & 59.20 & 18.29 & 54.16 \\
25.00 & 63.96 & 4.93 & 48.82 & 66.93 & 12.75 & 53.03 \\
Min & 31.21 & 4.93 & 43.62 & 38.09 & 12.75 & 46.95 \\
Max & 63.96 & 42.01 & 54.10 & 66.93 & 47.56 & 58.49 \\
\hline
\end{tabular}


In Table 7, it shows that clay has the smallest error $4.93 \%$ to $42.01 \%$ when compared to Topp theoretical values; and $12.75 \%$ to $47.56 \%$ when compared to Hallikainen theoretical values. Sand has the largest error in comparison to both Topp and Hallikainen values, which are $31.21 \%$ to $63.96 \%$, and $38.09 \%$ to $66.93 \%$ respectively.

Practical approach is developed to measure volumetric moisture in realistic environment where composition of the soil is unknown. In this scenario, further work is conducted to develop a General Equation that encompasses all soil types. Return Loss, $R L$ is plot against Volumetric Moisture, $\quad{ }_{v}$ for measured data on loamy, sand and clay. General Equation is formulated based on the best-fit curve on the measured data as shown in Figure 9 and (17). In this equation, return loss of General Equation, $R L_{G e n E q}$ is expressed in terms of volumetric moisture, $\quad v$.

$$
R L_{\text {Gen } E q}=-723.5 v^{3}+275.3 v^{2}-37.47 v+6.228
$$

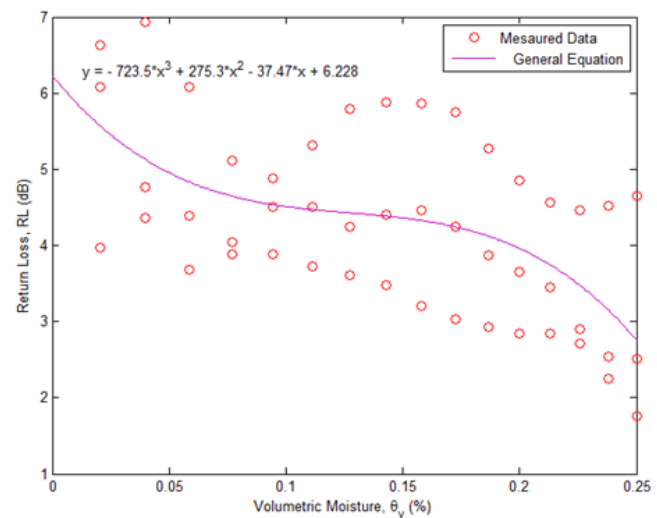

Figure 9. General Equation is formed with the data plots from individual measured data of clay, loamy, and sand.

\section{A Novel Optimization and Verification}

Further study is conducted to optimize theoretical Topp and Hallikainen curves into the General Equation. In our novel ideas, a general Equation, Topp curve and Hallikainen curve are formed as cubic polynomial equations as shown in (18) - (20).

$$
\begin{gathered}
y=a x^{3}+b x^{2}+c x+d \\
R L_{\text {Topp }}=29 \quad v^{3}+50 \quad v^{2}-41 \quad{ }_{v}+12 \\
R L_{\text {Hallikainen }}=0.02 v^{3}-0.38 v^{2}-30 \quad{ }_{v}+12
\end{gathered}
$$

where $a, b, c$, and $d$ are the polynomial coefficients of corresponding equations. For example, polynomial coefficient $a$, of Topp curve is 29 , whereas polynomial coefficient $b$ of Hallikainen curve is -0.38 . $R L_{T o p p}$ and $R L_{\text {Hall }}$ represents return loss of Topp curve and return loss of Hallikainen curve respectively, expressed in terms of volumetric moisture, $\quad v$. In polynomial equation, polynomial coefficient determines the characteristics of the curves. Optimization process begins from the source, which is the Topp curve or Hallikainen curve, and iterated to General Equation (Kaltofen, 2006). Five iterations are performed to transform the theoretical curves into General Equation. Each step of iteration is determined with progressive polynomial coefficient as shown in (21) - (23).

$$
\begin{gathered}
a_{m, \text { Topp }}=\left(\frac{a_{\text {GenEq }}-a_{\text {Topp }}}{n}\right) \times m \\
\left.y_{m}\right|_{\text {Topp }}=\left(a_{\text {Topp }}+a_{m, \text { Topp }}\right) x^{3}+\left(b_{\text {Topp }}+b_{m, \text { Topp }}\right) x^{2}+\left(c_{\text {Topp }}+c_{m, \text { Topp }}\right) x+\left(d_{\text {Topp }}+d_{m, \text { Topp }}\right) \\
\left.y_{m}\right|_{\text {Hall }}=\left(a_{\text {Hall }}+a_{m, \text { Hall }}\right) x^{3}+\left(b_{\text {Hall }}+b_{m, \text { Hall }}\right) x^{2}+\left(c_{\text {Hall }}+c_{m, \text { Hall }}\right) x+\left(d_{\text {Hall }}+d_{m, \text { Hall }}\right)
\end{gathered}
$$

where $n$ is the total number of iterations and m represents each step of the iterations. In this optimization, there are five iterations, thus $n=5$ and $\mathrm{m}$ ranges from 1 to 5 . Iterations in steps are essentially represented by $y_{m}$, which is defined by individual polynomial coefficient in $m$ steps, where $\left.y_{m}\right|_{\text {Topp }}$ are iterations for Topp curve and $\left.y_{m}\right|_{\text {Hall }}$ are iterations for Hallikainen currve. For example, first iteration of Topp curve with $m=1$ is represented by $\left.y_{l}\right|_{\text {Topp }}$ with polynomial coefficients $a_{1}, b_{1}, c_{1}$ and $d_{l}$. The abbreviation $a_{1, \text { Topp }}$ represents the first polynomial 
coefficient for optimization from Topp curve to General Equation. The first iteration is illustrated with (24) and (25).

$$
\begin{gathered}
a_{1, \text { Topp }}=\left(\frac{a_{\text {GenEq }}-a_{\text {Topp }}}{5}\right) \\
\left.y_{1}\right|_{\text {Topp }}=\left(a_{\text {Topp }}+a_{1, \text { Topp }}\right) x^{3}+\left(b_{\text {Topp }}+b_{1, \text { Topp }}\right) x^{2}+\left(c_{\text {Topp }}+c_{1, \text { Topp }}\right) x+\left(d_{\text {Topp }}+d_{1, \text { Topp }}\right)
\end{gathered}
$$

The polynomial coefficients $b, c$, and $d$ are determined by the same method as shown in (24). Iterations $2,3,4$ and 5 are determined using the same procedure. The process is repeated for iterations on Hallikainen curve with (23). The optimization results are as shown in Figure 10 and 11. Referring to Figure 10 and Figure 11, iteration 5 becomes the General Equation. Hence optimization is completed. The process is repeated with Hallikainen curve optimized to the General Equation.

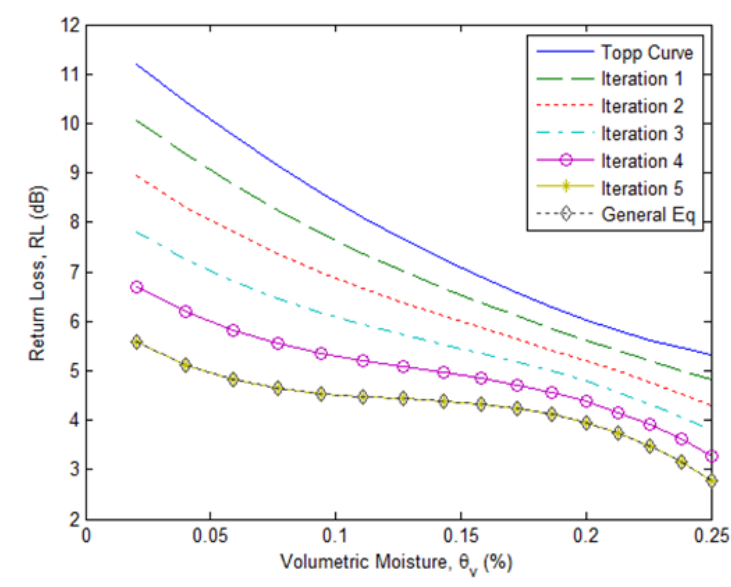

Figure 10. Topp curve optimized to General Equation

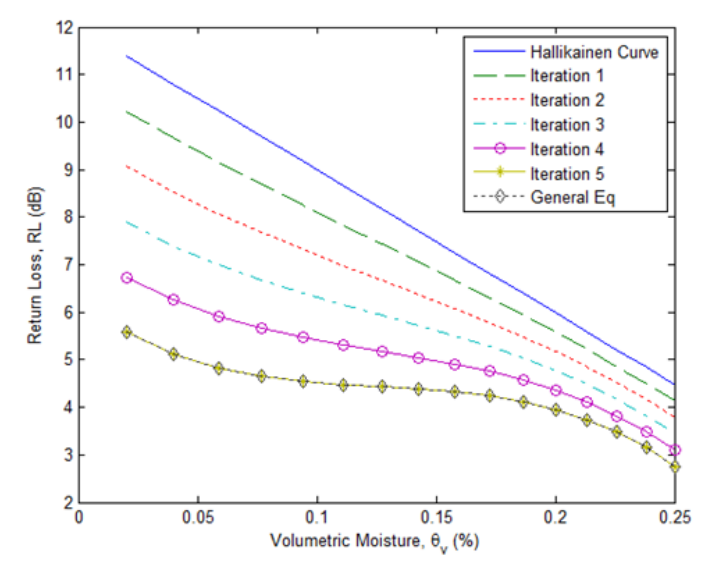

Figure 11. Hallikainen curve optimized to General Equation

Equation (17) correlates return loss to volumetric moisture in general. This new model is a critical contribution to the research, as the model undergoes validation process with different soil samples. A new soil type is developed with mixed sand and loamy soil, and this new sample undergoes the consistent procedure for volumetric moisture determination. Result from Figure 12 shows that volumetric moisture measurement is within the range of new equation. General Equation is verified to operate with allowable error. Prefix $M$ in the legend represents measured data. 


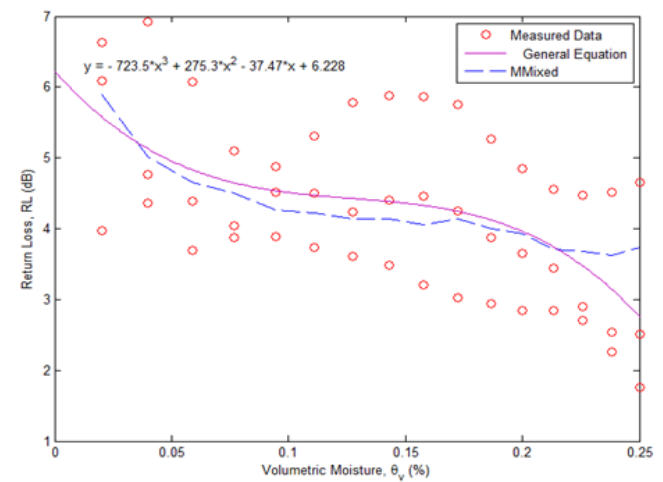

Figure 12. The experiment is repeated with the new type of soil and the measured data is plot with the General Equation

Further work had been performed with other new real soils. The performances of the return loss were measured and compared to the General Equation. Referring to Table 8, it shows that new soil type agrees well with the General Equation. From the soil with less than $21.31 \%$ volumetric moisture, the corresponding error is less than $7 \%$. This verifies that the model works with other general soil types.

Table 8. Measurement of new soil type is compared with General Equation for errors and verification.

\begin{tabular}{lllllll}
\hline No & $\begin{array}{l}\text { Volumetric } \\
\text { Moisture }(\%)\end{array}$ & $\begin{array}{l}\text { Return Loss } \\
\text { Equation }(\mathrm{dB})\end{array}$ & of General & $\begin{array}{l}\text { Return Loss of Mixed } \\
\text { Soil }(\mathrm{dB})\end{array}$ & $\begin{array}{l}\text { Error } \\
(\mathrm{dB})\end{array}$ & $\begin{array}{l}\text { Error } \\
(\%)\end{array}$ \\
\hline 1 & 2.04 & 5.57 & 5.89 & 0.32 & 5.72 \\
2 & 4.00 & 5.12 & 5.02 & 0.10 & 1.92 \\
3 & 5.88 & 4.83 & 4.65 & 0.18 & 3.74 \\
4 & 7.69 & 4.65 & 4.51 & 0.14 & 2.96 \\
5 & 9.43 & 4.54 & 4.26 & 0.28 & 6.06 \\
6 & 11.11 & 4.47 & 4.23 & 0.24 & 5.44 \\
7 & 12.73 & 4.43 & 4.13 & 0.29 & 6.64 \\
8 & 14.29 & 4.38 & 4.14 & 0.24 & 5.51 \\
9 & 15.79 & 4.33 & 4.06 & 0.27 & 6.16 \\
10 & 17.24 & 4.24 & 4.13 & 0.11 & 2.57 \\
11 & 18.64 & 4.12 & 4.00 & 0.12 & 2.92 \\
12 & 20.00 & 3.96 & 3.93 & 0.03 & 0.80 \\
13 & 21.31 & 3.74 & 3.70 & 0.04 & 1.05 \\
14 & 22.58 & 3.47 & 3.68 & 0.20 & 5.87 \\
15 & 23.81 & 3.15 & 3.62 & 0.47 & 14.96 \\
16 & 25.00 & 2.76 & 3.73 & 0.97 & 35.11 \\
\hline
\end{tabular}

Furthermore, the verified model is developed into a Graphical User Interface (GUI) with Matlab platform as in Figure 13. In this GUI, the user inputs return loss indicated from GPR device and soil moisture is determined per model. It cross references with the type of soil and determines bulk density. The bulk density is referred for the suitability for agriculture activity (USDA, 2008). 


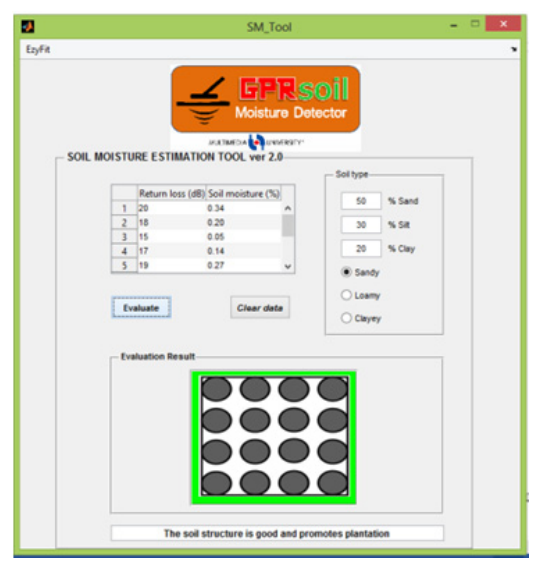

Figure 13. GUI developed in Matlab platform with model of the General Equation

\section{Conclusion}

In this article, we have presented novel soil moisture determination method via microwave surface reflection. The results from GPR measurement on clay, loamy and sand have been analyzed and the results are found in good agreements with Topp and Hallikainen method. Optimization and verification are performed on the results for model development. The results are further verified with a new soil type on the same procedure. Microwave surface reflection method is useful for the researchers who wish to evaluate soil moisture using the same parameters as discussed in this article. The novel feature that contributed is the development of the soil moisture equation as an application of non-destructive technique for future engineering applications.

\section{References}

Abdullah, R. S., \& Raja, A. et al. (2009). Evaluation of road pavement density using ground penetrating radar. Journal of Environmental Science and Technology, 2(2), 100-111.

Amineh, Reza K., Ravan, M., Trehan, A., \& Nikolova, N. K. (2011). Near-field microwave imaging based on aperture raster scanning with TEM horn antennas. IEEE Transactions on Antennas and Propagation, 59(3), 928-940.

Argonne National Laboratory (2014). Volumetric water content. Argonne National Laboratory. Retrieved August 15, 2014, from http://web.ead.anl.gov/resrad/datacoll/volcont.htm

British Standard Institution. (1990). British standard methods of test for soils for civil engineering purposes: Part 2: classification tests. London: BSI.

Daniels, D. J. et al. (1988). Introduction to subsurface radar. IEEE Proceedings, 135(4).

Daniels, D., \& Skolnik, M. (2008). Radar Handbook ( $3^{\text {rd }}$ Ed). USA: McGraw Hill.

De Kool, M., Rawlinson, N., \& Sambridge, M. (2006). A practical grid-based method for tracking multiple refraction and reflection phases in three-dimensional heterogeneous media. Geophysical Journal International, 167(1), 253-270.

Geuzaine, C., Bruno, O., \& Reitich, F. (2005). On the O(1) solution of multiple-scattering problems. IEEE Transactions on Magnetics, 41(5), 1488-1491.

Hallikainen, T. M. et al. (1985). Microwave dielectric behavior of wet soil - part I: models and experimental observations, IEEE Transactions on Geoscience and Remote Sensing, GE-23(1), 25-34.

Hasar, U. C. (2009). Non-destructive testing of hardened cement specimens at microwave frequencies using a simple free-space method. $N D T \& E$ International, 42(6), 550-557.

Huisman, J. A. et al. (2003). Measuring soil water content with ground penetrating radar: a review, Vadose Zone Journal, 2(4), 476-491.

Jusoh, M. A. et al. (2011). Determination of moisture content in mortar at near relaxation frequency $17 \mathrm{GHz}$, Measurement Science Review, 11(6), 203-206.

Kaatze, U., Kupfer, K., \& Hubner, C. (2007). Microwave moisture measurements, Measurement Science and Technology, 18(4). 
Kaltofen, E., Zheng, F. Y., \& Li, H. Z. (2006). Approximate greatest common divisors of several polynomials with linearly constrained coefficients and singular polynomials. Proceedings of the 2006 International Symposium on Symbolic and Algebraic Computation, ACM, 169-176.

Peters, J. R. L. et al. (1984). Ground penetrating radar as a subsurface environmental sensing tool, IEEE.

Tarantino, A., Ridley, M. A., \& Toll, G. D. (2009). Field measurement of suction, water content, and water permeability, Laboratory and Field Testing of Unsaturated Soils, 139-170.

Topp, G. C., Davis, J. L., \& Annan, A. P. (1980). Electromagnetic determination of soil water content: measurements in coaxial transmission lines. Water Resources Research, 16(3), 574-582.

Turk, S., Ahmed, H., Koksal, A., \& Alexey, A. (2011). Vertiy: Subsurface Sensing, Wiley, 62.

USDA. (2008). Soil quality indicators. USDA Natural Resources Conservation Service. Retrieved December 15, 2014, from http://www.nrcs.usda.gov/Internet/FSE_DOCUMENTS/nrcs142p2_053256.pdf

Zhao, Y. et al. (2010). Relative bulk density as a measure of compaction and its influence on tree height, Canadian Journal of Forest Research, 40, 1724-1735.

\section{Copyrights}

Copyright for this article is retained by the author(s), with first publication rights granted to the journal.

This is an open-access article distributed under the terms and conditions of the Creative Commons Attribution license (http://creativecommons.org/licenses/by/3.0/). 